\title{
Methodology for identifying technical details of smart energy solutions and research gaps in smart grid: an example of electric vehicles in the energy system
}

\author{
Kristoffer Christensen ${ }^{1 *}$, Zheng $\mathrm{Ma}^{2}$, Yves Demazeau ${ }^{3}$ and Bo Nørregaard Jørgensen ${ }^{1}$ \\ From 1st Energy Informatics.Academy Conference Asia \\ Beijing, China . 29-30 May 2021
}

\footnotetext{
* Correspondence: kric@mmmi.sdu. $\mathrm{dk}$

${ }^{1}$ Center for Energy Informatics, Mærsk Mc-Kinney Møller Institute, University of Southern Denmark, 5230 Odense, Denmark Full list of author information is available at the end of the article
}

\begin{abstract}
Simulations, especially agent-based simulation, are able to facilitate the investigation of smart energy solutions and business models, and their impacts on the energy system and involved stakeholders. Technical details, alternatives, and multiple options for what-if scenarios influence simulation quality, but no methodology available to support the investigation. This paper proposes a method for identifying technical details of smart energy solutions in the energy system and identifying research gaps in the smart grid context with EV solutions as an example. The method includes the investigation of the state-of-the-art EV solutions by scoping review and the allocation of the scoping review results into the Smart Grid Architecture Model framework with three dimensions (Domains, Zones, and interoperability layers). The quantitative scoping review results in a total number of 240 references and 10 references match the criteria based on the qualitative scoping review. The results show that the most popular EV use case within the targeted scope is the V2G concept, and 6 out of the 10 references discuss the EVs' potentials to work as energy storage. Seventeen features are identified by mapping the EV use cases (solutions and business models) into the three dimensions (domain, zone, and interoperability layers) of the SGAM framework. The process at the Zone layer is the most popularly covered (mentioned 64 times), and enterprise at the Zone layer and communication in the interoperability layer are the least covered (mentioned 4 times each).
\end{abstract}

Keywords: Electric vehicle, Smart energy solution, Business model, Smart grid, Methodology (c) The Author(s). 2021 Open Access This article is licensed under a Creative Commons Attribution 4.0 International License, which permits use, sharing, adaptation, distribution and reproduction in any medium or format, as long as you give appropriate credit to the original author(s) and the source, provide a link to the Creative Commons licence, and indicate if changes were made. The images or other third party material in this article are included in the article's Creative Commons licence, unless indicated otherwise in a credit line to the material. If material is not included in the article's Creative Commons licence and your intended use is not permitted by statutory regulation or exceeds the permitted use, you will need to obtain permission directly from the copyright holder. To view a copy of this licence, visit http://creativecommons.org/licenses/by/4.0/. 


\section{Introduction}

The increasing number of renewable energy sources in the energy system can contribute significantly to reduce the impacts caused by climate change. However, it will create the challenge of grid imbalance, and demand response is a promising solution (Ma et al. 2017a). Electric Vehicles (EVs) are expected to play an important role in balancing the integration of renewable energy resources in the Smart Grid. The Danish Energy Agency estimates from an extrapolation that EVs and plug-in hybrid vehicles will account for $9 \%$ of the total Danish vehicle stocks by 2030 (Energistyrelsen 2019). EV smart charging has been well discussed together with flexible electricity prices as a means to provide demand response (Fatras et al. 2021). Moreover, in a Smart Grid with two-way power- and communication-flow between consumers and the grid it is possible to enable Vehicle-to-Grid (V2G), i.e. allowing EVs to provide power to the grid from their battery (Fatras et al. 2020). V2G can utilize EVs' battery capacity in the grid as energy storage (Li et al. 2012; McGee et al. n.d.). Especially, hourly electricity prices (Ma and Jørgensen 2018) and dynamic tariffs (Ma et al. 2021) provide significant financial benefits for EVs to provide implicit demand response, and the unbundling electricity markets (e.g., the Nordic spot markets (Zheng et al. 2016)) provides more opportunities for the explicit demand response (Ma et al. 2017b).

However, the increasing number of EVs in the distribution grid and smart charging, especially simultaneously EV charging, might cause grid overload. Meanwhile, various stakeholders are involved in different scenarios, e.g., EV owners, distribution system operators (DSO), charging box providers, and electricity suppliers are involved in EV home charging, their benefits and barriers remain unclear (Ma et al. 2018). Therefore, it is important to investigate EV-related smart energy solutions and business models, and their impacts on the energy system and involved stakeholders.

The studies in energy flexibility based on the agent-based simulation, e.g., commercial greenhouses (Howard et al. 2020a; Christensen et al. 2020a; Christensen et al. 2020b), water supply (Værbak et al. 2019), and breweries (Howard et al. 2020b), show that the agent-based simulation can serve this purpose, especially support the investigation of what-if scenarios (Ma et al. 2019). Meanwhile, related stakeholders and their interactions can be identified with the energy ecosystem modeling methodology proposed by (Ma 2019a). Furthermore, the barriers and opportunities and barriers for adopting energy flexibility have been investigated in the literature, e.g., (Ma et al., n.d.; Billanes et al. 2017).

However, technical details influence the simulation quality, and little literature has provided a methodology for identifying technical details of EVs in the energy system. Meanwhile, simulations for the what-if scenarios should be based on alternatives and multiple options, and overviews and research gaps of the related domains are essential. However, the majority of the literature is mainly case-based.

Therefore, this paper aims to propose a method for identifying technical details of smart energy solutions in the energy system and identifying research gaps in the smart grid context with EV solutions as an example. The method includes the investigation of the state-of-the-art EV solutions by scoping review and the allocation of the scoping review results into the Smart Grid 
Architecture Model (SGAM) framework (CEN-CENELEC-ETSI Smart Grid Coordination Group 2012). The SGAM framework is an EU standard for the smart grid, and it not only can provide an architectural viewpoint but also technical details with its three dimensions and multiple layers (Ma et al. 2020).

This paper firstly introduces the methodologies of the scoping review method for identifying relevant articles, and the SGAM framework method for analyzing and reviewing the identified articles. The results are presented after the Methodology Section, which consists of a mapping and analysis of the identified articles in the SGAM framework. Following the Result Section, the Discussion Section discusses the findings and limitations of the presented methodology. A summary and conclusion are presented in the conclusion section.

\section{Methodology}

\section{Literature search and collection}

This paper uses the scoping review method for the literature search and collection regarding EV smart energy solutions and business models in the energy system. A scoping review aims to map rapidly the key concepts underpinning a research area (Ma et al. 2019; Arksey and O'Malley 2005). A scoping review can be used to: examine the extent, range, and nature of research activity; determining the value of undertaking a full systematic review; summarize and disseminate research findings; identify research gaps in the existing literature (Arksey and O'Malley 2005). This study uses the scoping review to summarize and disseminate the research findings. The used approach starts by designing a search string for relevant databases. The overall purpose is to find EVrelated smart energy solutions and business models. Hence, five databases are chosen based on the relevance of the domain:

- Academic Search Premier EBSCO

- ACM Digital Library

- IEEE Xplore

- Web of Science

- Science Direct

Academic Search Premier EBSCO, Web of Science, and Science Direct include a wide range of research fields including engineering and social science. They are included in the paper to make sure that business-related articles are covered. Many smart energy solutions are related to information technology and computing, in particular, EVs' charging solutions. Therefore, the ACM Digital Library database is included. IEEE Xplore is included due to its focus on electrical engineering, computer science, and electronics.

The following search string is an example of a string used for the database of Web of Science.

(TI=((smart OR intelligent) AND (energ* OR electric* OR heat*) AND (solution* OR technolog* OR product* OR service*)))

The search string is modified for the other databases following their searchingsystem syntax. From the search results, the keywords "business model" and "solution" are used to reduce the results. 


\section{Literature analysis}

In the literature search results, all titles or abstracts including EVs are chosen to be implemented in the SGAM framework. The SGAM framework provides a smart grid architecture and illustrates the complexity of the smart grid (Ma 2019b). The SGAM framework methodology consists of seven principles: universality, localization, consistency, flexibility, scalability, extensibility, and interoperability (CEN-CENELECETSI Smart Grid Coordination Group 2012). The principles build the framework that is visualized in Fig. 1.

The SGAM framework represents smart grid architectures in a common and neutral view. Placing entities to the appropriate location and thereby mapping them in the framework by their domains, zones, and interoperability layers. Consistent mapping means that all layers are covered with an appropriate entity. Inconsistency (missing layers) shows that there is a need for specification or standard in order to realize the solution. By mapping the entities for a given smart energy solution, it is possible to validate the support by standards; identify gaps in respect to standards, map existing architectures into a general view, and develop smart grid architectures (Ma et al. 2019; CEN-CENELEC-ETSI Smart Grid Coordination Group 2012). The definition of each dimension and the description of all zones, domains, and operability layers are shown in Table 1.

In the SGAM framework, use cases are identified and mapped with the required information of: Name, scope, and objective; case diagram; actor names, types; preconditions, assumptions, postconditions; use case steps; information which is exchanged among actors. (CEN-CENELEC-ETSI Smart Grid

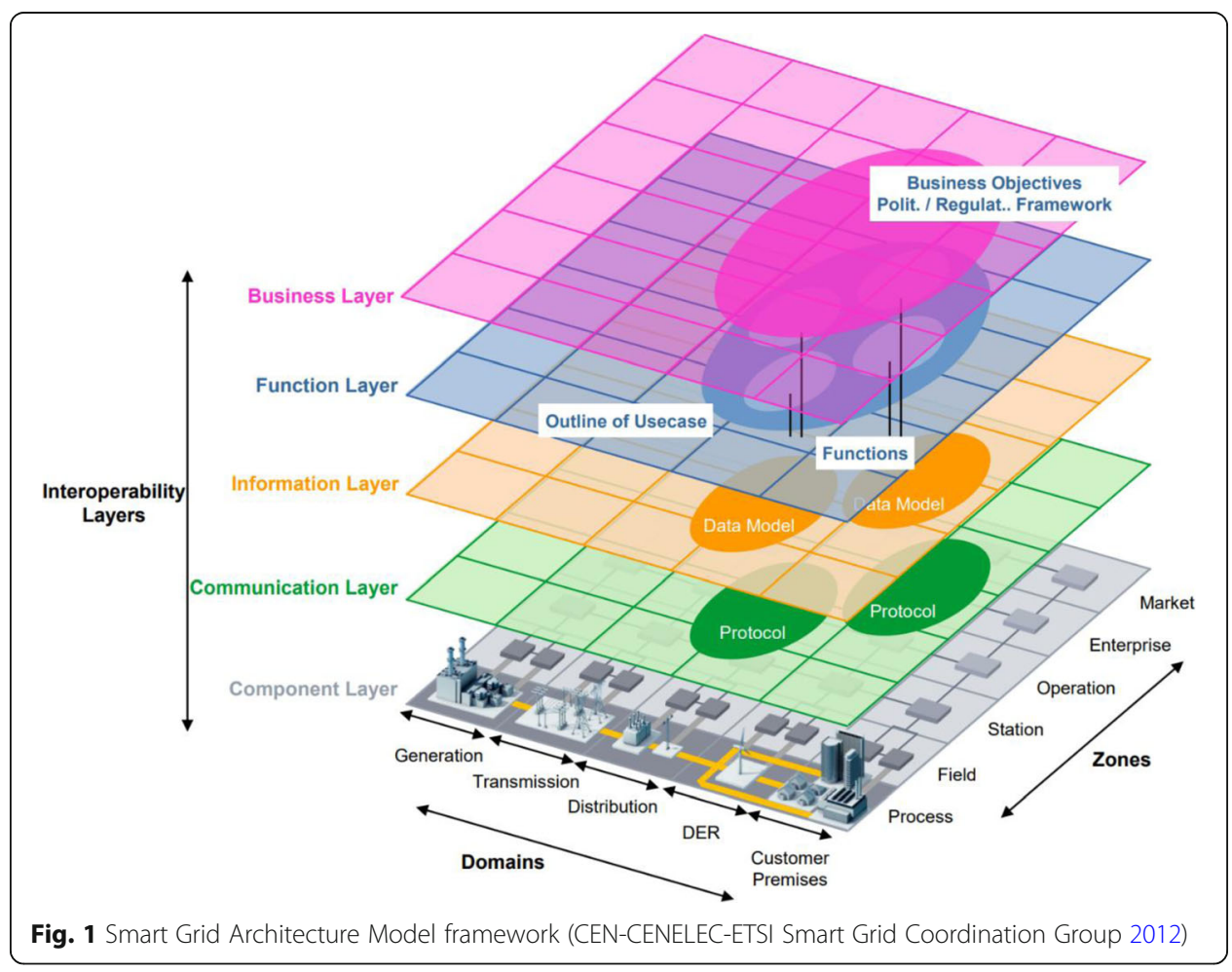


Table 1 Terms and definition in the SGAM framework (CEN-CENELEC-ETSI Smart Grid Coordination Group 2012)

\begin{tabular}{|c|c|c|}
\hline & & Description \\
\hline \multirow[t]{3}{*}{ Terms } & $\begin{array}{l}\text { SGAM Interoperability } \\
\text { Layer }\end{array}$ & $\begin{array}{l}\text { To allow a clear presentation and simple handling of the architecture } \\
\text { model, the interoperability categories described in the GridWise } \\
\text { Architecture model are aggregated in SGAM into five abstract } \\
\text { interoperability layers. }\end{array}$ \\
\hline & SGAM Domain & $\begin{array}{l}\text { One dimension of the Smart Grid Plane covers the complete } \\
\text { electrical energy conversion chain, partitioned into } 5 \text { domains. }\end{array}$ \\
\hline & SGAM Zone & $\begin{array}{l}\text { One dimension of the Smart Grid Plane represents the hierarchical } \\
\text { levels of power system management, partitioned into } 6 \text { zones. }\end{array}$ \\
\hline \multirow[t]{5}{*}{ Domain } & Generation & $\begin{array}{l}\text { Representing of electrical energy in bulk quantities, typically } \\
\text { connected to the transmission grid. }\end{array}$ \\
\hline & Transmission & Representing the transmission infrastructure and organization. \\
\hline & Distribution & Representing the distribution infrastructure and organization. \\
\hline & $\begin{array}{l}\text { Distributed Energy } \\
\text { Resources (DER) }\end{array}$ & $\begin{array}{l}\text { Representing distributed electrical resources directly connected to } \\
\text { the public distribution grid. }\end{array}$ \\
\hline & Customer Premises & $\begin{array}{l}\text { Representing electricity consumers and producers of electricity. This } \\
\text { includes industrial, commercial, and home facilities. Production from } \\
\text { consumer generation such as photovoltaic, EV storage, batteries, } \\
\text { micro turbines, etc. are included in this domain. }\end{array}$ \\
\hline \multirow[t]{6}{*}{ Zone } & Process & $\begin{array}{l}\text { Physical, chemical, or spatial transformations of energy and the } \\
\text { physical equipment directly involved e.g. generators and } \\
\text { transformers. }\end{array}$ \\
\hline & Field & $\begin{array}{l}\text { Equipment to protect, control, and monitor the process of the power } \\
\text { system, e.g. protection relays and bay controller. }\end{array}$ \\
\hline & Station & $\begin{array}{l}\text { Areal aggregation level for field level, e.g. data concentration, } \\
\text { functional aggregation, and local Supervisory Control And Data } \\
\text { Acquisition (SCADA) systems. }\end{array}$ \\
\hline & Operation & $\begin{array}{l}\text { Power system control operation in the respective domain, e.g. } \\
\text { energy management systems in generation and transmission systems } \\
\text { and EV fleet charging management systems. }\end{array}$ \\
\hline & Enterprise & $\begin{array}{l}\text { Commercial and organizational processes, services, and } \\
\text { infrastructures for enterprises (utilities, service providers, energy } \\
\text { traders), e.g. asset management, logistics, work force management, } \\
\text { staff training, customer relation management, billing and } \\
\text { procurement. }\end{array}$ \\
\hline & Market & $\begin{array}{l}\text { Market operations possible along the energy conversion chain, e.g. } \\
\text { energy trading and retail market. }\end{array}$ \\
\hline \multirow[t]{5}{*}{ Interoperability } & Business & $\begin{array}{l}\text { Represents the business view on the information exchange related } \\
\text { to smart grids. Regulatory and economic structures, policies, business } \\
\text { models, business portfolios of market parties relate to this layer. }\end{array}$ \\
\hline & Function & $\begin{array}{l}\text { Function and services including their relationships from an } \\
\text { architectural viewpoint. The functions are represented independently } \\
\text { from actors and physical implementations in applications, systems, } \\
\text { and components. }\end{array}$ \\
\hline & Information & $\begin{array}{l}\text { The information that is being used and exchanged between } \\
\text { functions, services, and components. }\end{array}$ \\
\hline & Communication & $\begin{array}{l}\text { Describe protocols and mechanisms for the interoperable exchange } \\
\text { of information between components in the context of the } \\
\text { underlying use case, function or service, and related information } \\
\text { objects or data models. }\end{array}$ \\
\hline & Component & $\begin{array}{l}\text { Physical distribution of all participating components in the smart grid } \\
\text { context. }\end{array}$ \\
\hline
\end{tabular}


Coordination Group 2012) uses the term "use case" for solutions in the smart grid, for example, the use case "control reactive power of Distributed Energy Resources (DER) unit". This paper maps the use cases found in the literature into the SGAM framework based on the domains, zones, and interoperability layers. This approach is used to identify missing entities in the literature from a smart grid architecture point of view.

Five steps of the literature analysis are conducted based on the SGAM framework:

- The first step is to map all physical components from the use cases to the component layer. Examples of components are controllers, computers, the grid, EVs, and transformers. These components are derived from actors' information, as actors can be of type, devices, applications, persons, and organizations.

- The next step is to map the business layer. The "domains" and "zones" covered by the components compose an area. The business objectives, economic, and regulatory constraints included in this area influence the mapped use case. These objectives and constraints are located in the business layer and need to be taken into account as non-functional requirements for implementations. In the third step, the needed functions from different components are mapped into the function layer, e.g. DER control for a controller and SCADA for SCADA system components.

- The fourth step is to add information flows into the information layer. The layer is divided into a business context and a canonical layer. The business context layer describes the information flow, such as sending voltage measurement. Whereas, the canonical information layer is describing the standards such as CIM standard (IEC 61968-4) which is appropriate for exchanging information objects in the "enterprise" and "operation" zones (CEN-CENELEC-ETSI Smart Grid Coordination Group 2012).

- At the last step, the communication standards are mapped into the communication layer, e.g. IEC 61850 which is the state-of-the-art communication protocol in power system automation (CEN-CENELEC-ETSI Smart Grid Coordination Group 2012). Meanwhile, it should be clear which roles are responsible for which functions when realizing the business process. In case that an entity cannot be assigned any role the

Table 2 Literature search

\begin{tabular}{lll}
\hline Search Results & & \\
\hline Search String & Database & Results \\
\hline $\begin{array}{l}\text { "Document Title":(smart OR intelligent) AND (energy OR electricity OR heat*) AND } \\
\text { (solution OR product OR technology OR service) }\end{array}$ & IEEE Xplore & 137 \\
$\begin{array}{l}\text { acmdlTitle:(+(smart intelligent) + (energy electric heat) + (solution product technology } \\
\text { service)) }\end{array}$ & ACM Digital & 66 \\
TI (smart OR intelligent) AND (energy OR electric OR heat) AND (solution OR & EBSCO & 32 \\
technology OR product OR service) & & \\
(TI= ((smart OR intelligent) AND (energ* OR electric* OR heat*) AND (solution* OR & Web of & 26 \\
technolog* OR product* OR service $\left.\left.{ }^{*}\right)\right)$ & Science & \\
(smart OR intelligent) AND (energy OR electric OR heat) AND (solution OR & Science Direct & 21 \\
technology OR product OR service) & & \\
\hline
\end{tabular}


responsibility for that element is unclear and calls for further investigation before realization.

\section{Literature search results}

This section presents the scoping review search results. Table 2 shows the used search strings for the different databases including the literature results after removing all duplicates. The removal of all duplicates is done after all searches have been performed and citations are downloaded to the reference management software tool, which in this case is EndNote X9 (Zhu et al. 2016). A literature search is done before the one seen in Table 2 for practicing search strings in different databases. The search criteria are overall based on smart energy solutions and business models within that field. The search is based only on title results to reduce the number of results. Synonyms and notations for the different searching keywords are used to make sure relevant literature is not excluded. For example, the keyword 'energy' is also representing electricity and heating.

From the searching results shown in Table 2 and the initial practicing search, a total of 558 results are found. The found results' citations are downloaded to EndNote. In EndNote a keyword search on the keywords of 'solution', 'business model', and 'solution AND (business model)' is used to remove non-relevant literature. Table 3 shows that a total number of 240 references are related to the scope.

The last step of the quantitative scoping review search process is to identify literature for the qualitative scoping review analysis. To do so, the 240 references' titles and abstracts are evaluated and assessed into different categories. The categories are physical components/technologies, software, service, smart house/building, and EV oriented. EV-oriented smart energy solutions are chosen as an example of how to use the SGAM framework in practice. Ten articles are found to be EV-oriented and are selected for the qualitative scoping review analysis. Table 4 shows the 10 articles with a description of their key aspects.

This paper analyzes the use cases in each article in detail and matches the use cases with the three dimensions of the domain, zone, and interoperability in the SGAM framework. Seventeen features have been identified through a thorough analysis process (shown in Table 5). Meanwhile, Table 11 in the APPENDIX explains how the 17 identified features are identified based on the literature analysis with the three dimensions of interoperability layer, domain, and zone of the SGAM framework.

For instance, Feature 1 represents the EV in the component interoperability layer and energy storage through V2G in the function layer. Feature 2 represents in the component layer a charging point having a communication technology. The

Table 3 Relevant search results

\begin{tabular}{lc}
\hline Keyword search & Results \\
\hline Solution & 189 \\
Business model & 51 \\
Solution AND (business model) & 1 \\
\hline
\end{tabular}


Table 4 Selected references with focuses on electric vehicle-oriented solutions

Article

Electric Vehicle Charging: Transformer Impacts and Smart, Decentralized Solutions

(Hilshey et al. 2012)

An Energy Efficient Solution: Integrating PlugIn Hybrid Electric Vehicle in Smart Grid with Renewable Energy

Vehicle to grid: electric vehicles as an energy storage solution

Security and privacy of electric vehicles in the smart grid context: problem and solution

Optimal Solution of Plug in Hybrid Electric Vehicles to Minimize Cost and Emission in a Smart Grid - A Developing Country View

A Novel ICT Solution for Electric Vehicles Integration on Smart Grids

Adaptive three-phase power-flow solution for smart grids with plug-in hybrid electric vehicles
(Li et al. 2012) n.d.) 2013) 2015)

(Yang and Tseng 2015)

\section{Solution \& Business models}

Smart charging as a solution to reduce transformer aging. 2 smart-charging strategies preventing the transformer from overload are compared. The paper uses the transformer as the charge manager at AC level I and II.

Stochastic programming optimization to solve power management problem and minimize cumulative cost over all stages. 2 cases: optimizing for a system using thermal power plants, wind turbines, and diesel generators; a fleet of plug-in EVs that can be used as energy storage.

(McGee et al. A charging system design that can utilize EV battery capacity as energy storage through V2G. The system has been successfully tested on a fleet of EVs.

(Nicanfar et al. Two authentication schemes to preserve customers' privacy. This paper's focus is on the security and privacy requirements of EVs in the smart grid especially when the EV acts as energy storage.

(Ahmad and The paper uses a multi-objective minimization Sivasubramani cost and emissions in the smart grid. The integration of EVs in the grid and the V2G concept are in focus.

(Santos et al. An ICT architecture that supports an energy 2015) management algorithm aiming to optimize the EV charging and storage capabilities accordingly with economical and technical considerations. The energy management algorithm uses dynamic tariffs, electric loads, and end-users' preferences and comfort requirements.

An adaptive three-phase power flow method. Two solution strategies are used to adapt the network typologies of radial and non-radial smart grid. The method is found to be accurate, efficient, and adaptable in smart grids with EV charging demands. The paper's focus is on solving the unbalanced power-flow problem in a smart grid having EVs and distributed energy sources.

(Budde Christensen et al. 2012)
Can innovative business models overcome resistance to electric vehicles? Better Place and battery electric cars in Denmark
An innovative business model for EVs to eliminate consumer's risk of degrading EV battery over time by leasing batteries, coordinating the charging and infrastructure The consumer subscribes to a fixed mileage limit and charges at the charging spots and battery switching stations. Intelligent charging when electricity price is low and second-life of batteries are considered.

(Rezania and

V2G, Grid-to-Vehicle (G2V), and second life Business models for the integration of electric vehicles into the Austrian energy system

Business model of clean energy vehicles industry based on option Prüggler 2012

business models. Furthermore, the business models include participation opportunities in the Austrian control market.

(Zhong and Four business models: the whole EV selling You 2012) mour business models: the whole EV selling
mole EV leasing model, battery leasing model, and financial leasing model. The paper focuses on the financial leasing model (a finance company purchasing an asset and leases that asset to a client that after the leasing period typically has the opportunity to purchase the asset at a low 
Table 4 Selected references with focuses on electric vehicle-oriented solutions (Continued)

\begin{tabular}{|c|c|c|}
\hline Article & Ref. & Solution \& Business models \\
\hline & & $\begin{array}{l}\text { price). Following aspects are included: a } \\
\text { dynamic pricing method; partial differential } \\
\text { equation model to describe the financial } \\
\text { aspects of the EV price; integral linear } \\
\text { programming method; solving model by finite } \\
\text { difference method. }\end{array}$ \\
\hline
\end{tabular}

charging points both charge EVs and communicate with the smart grid. Hence, it locates between the zones of Process and Field, and between the domains of Customer premises and DER. Feature 2 further includes a public key encryption system and identity-based cryptography in the communication layer. In the function layer, feature 2 represents sending user identity to a control unit. Feature 10 represents identity-based cryptography in the communication layer and EV identity in the information layer.

(Nicanfar et al. 2013) has features of 1, 2, 10,11, 12, and its use case may include some implicit entities, however, during the analysis process, this paper only uses the descriptions stated and included in each selected article. Therefore, to realize the (Nicanfar et al. 2013)'s use case in the smart grid, some entities are needed as a minimum, e.g. communication and information standards and charging functions. All papers implicitly indicate that the grid (including transformers) is presented in the component layer with the link between all domains in the process zone. Hence, the grid is not in Table.

Table $\mathbf{5}$ Identified 17 features

\begin{tabular}{ll}
\hline Number & Feature \\
\hline 1 & EVs or PHEVs as storage for V2G \\
2 & Communication between EVs and the grid \\
3 & Smart charging algorithm in the charge management device \\
4 & EV and battery charging at charging stations \\
5 & Optimization in fleet charging management \\
6 & Generation units considering the number of EVs \\
7 & EV charging based on electricity production by DERs \\
8 & Charging equipment enables V2G \\
9 & Participation in electricity markets \\
10 & Communication between EVs and charging equipment \\
11 & EV charging at public charging points/ fast-charging stations \\
12 & Data collector or database (data center) \\
13 & Grid operator or DSO control operations \\
14 & Load management by DSO, energy scheduler, and data aggregator \\
15 & Communication between EV and aggregator \\
16 & Communication between EVs and energy scheduler and data aggregator \\
17 & A broker between EV owner and energy market \\
\hline
\end{tabular}




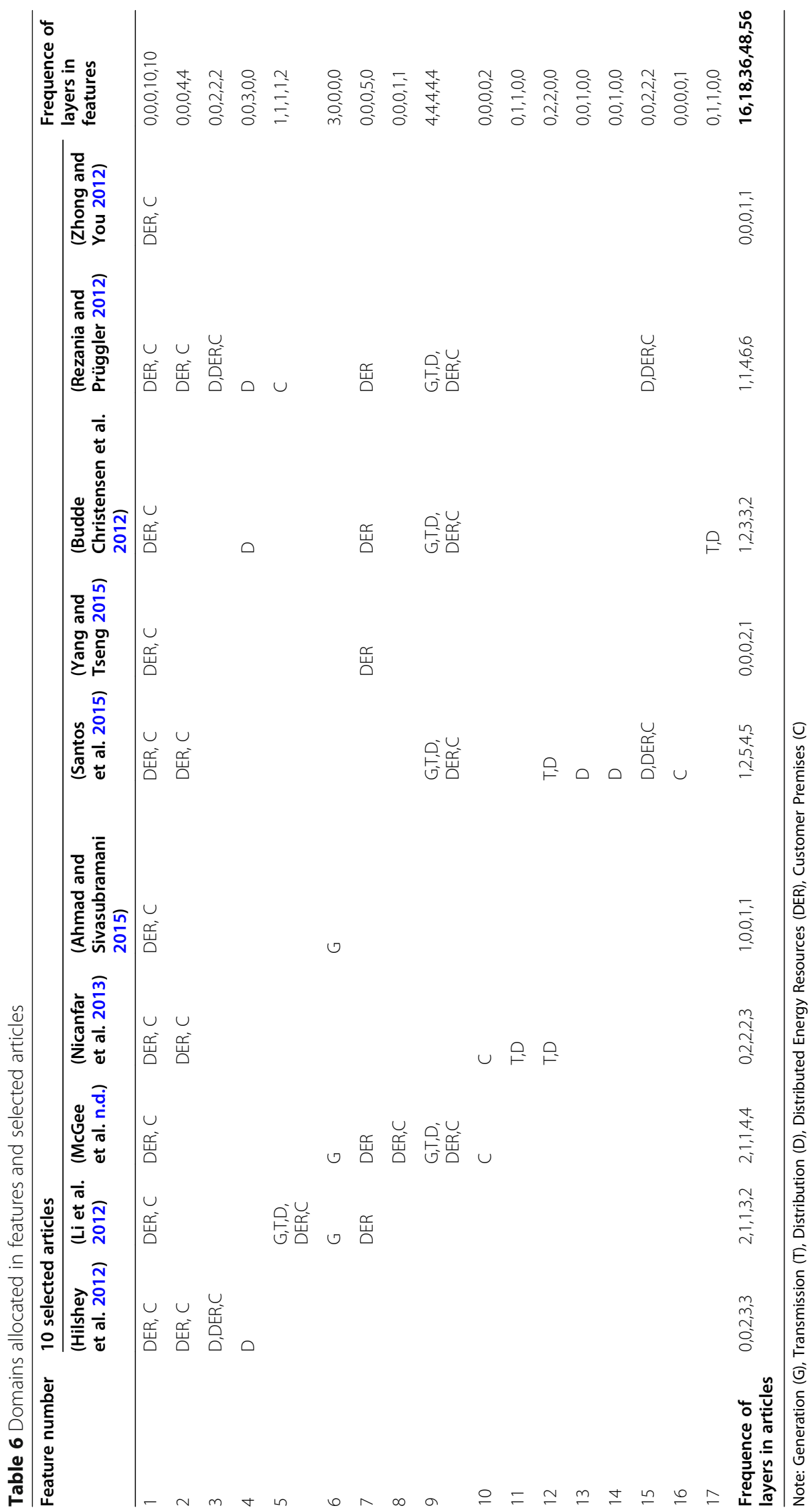




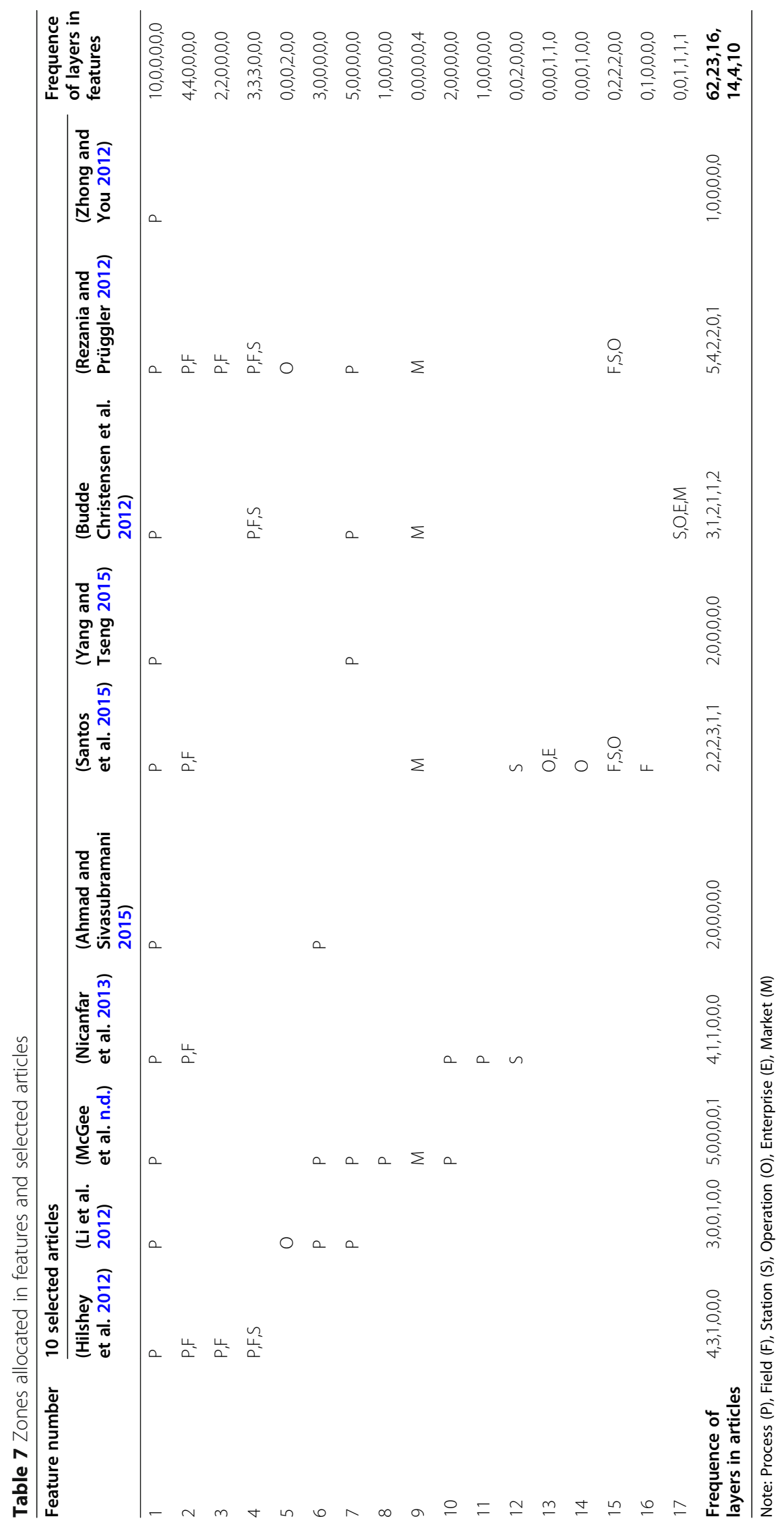




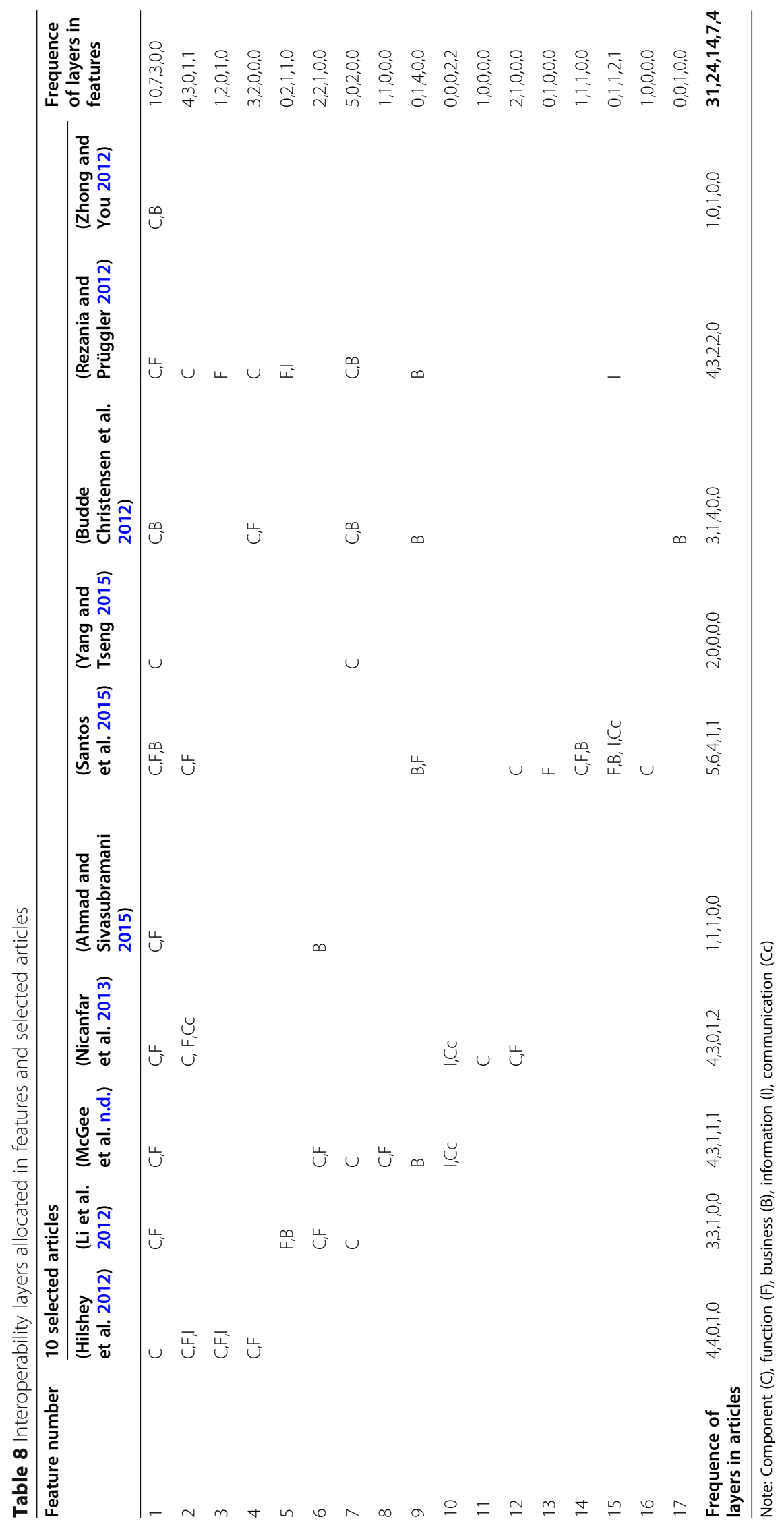




\section{Result and analysis}

This paper further matches the identified 17 features in the use cases in the literature (EVs' roles: solutions and business models) into each layer of the SGAM framework (shown in Tables 6, 7, and 8).

Table 6 shows how the identified features are allocated in the Domains. The Domains are presented in the table as the Generation (G), Transmission (T), Distribution (D), Distributed Energy Resources (DER), Customer Premises (C) in the SGAM framework. As shown in Table 6, the Distributed Energy Resources (DER) and Customer Premises (C) are the most frequent Domains presented in the selected articles and the features which have been discussed 48 and 56 times, respectively.

For instance, in Feature 15, use cases in (Santos et al. 2015; Rezania and Prüggler 2012) include distribution (D), Distributed Energy Resources (DER), and customer premises (C) Domains. For (Santos et al. 2015), the communication standards, such as ISO 15118, and information flow (e.g. EV's State-of-Charge) are between the charging point located in Feature 2 and the energy scheduler in Feature 14. Thus, feature 15 is a link between these features, thereby covering the three Domains (distribution, DER, and customer premises). For (Rezania and Prüggler 2012), the information flow of the EV's driving pattern is the link between the charging point (feature 2) and the aggregator (feature 14). Feature 6 is only in the generation (G) Domain as the feature includes thermal power plants in reference (Li et al. 2012; McGee et al. n.d.), and power plant cost minimization for (Ahmad and Sivasubramani 2015).

Table 7 shows the 17 features allocate at the Zones. The Zones are presented in the table as the Process (P), Field (F), Station (S), Operation (O), Enterprise (E), Market (M) in the SGAM framework. As shown in Table 6, the Process (P) and Field (F) are the most frequent Zones presented in the selected articles and the features which have been discussed 62 and 23 times, respectively.

For instance, in Feature 4, use cases in the 3 articles (Hilshey et al. 2012; Budde Christensen et al. 2012; Rezania and Prüggler 2012) include the process (P), field (F), and station (S) Zones. For (Hilshey et al. 2012)'s use case, the process Zone is the transformation of the voltage level from medium to low voltage. Both (Budde Christensen et al. 2012; Rezania and Prüggler 2012)'s use cases involve charging stations (including battery switching stations for (Budde Christensen et al. 2012)), hence the process of charging the EVs is present in this feature. The transformer in (Hilshey et al. 2012)'s use case includes protection equipment and can be part of a substation placing the use case in the field and station Zone. The charging/ battery switching station in (Budde Christensen et al. 2012)'s use case contains a smart meter and control device managing the charging of the EVs placing the use case in both field and station Zone. For (Rezania and Prüggler 2012)'s use case, the aggregation of charging EVs including field equipment (see Table 1) places the use case in the field and station zone.

Table 8 shows the interoperability layers that the selected article and features include. The interoperability layers are presented in the table as the component $(C)$, function $(\mathrm{F})$, business (B), information (I), and communication (Cc) that are defined in the SGAM framework. As shown in. 
Table 8, the interoperability layers of component (C) and function (F) are the most frequent layers presented in the selected articles and the features which have been discussed 31 and 24 times, respectively.

For instance, in feature 2, use cases in 4 articles include the component (C) layer. For use cases of (Hilshey et al. 2012; Rezania and Prüggler 2012), the component layer of feature 2 is the smart meter (Advanced Metering Infrastructure), and for use cases of (Nicanfar et al. 2013; Santos et al. 2015), the component layer of feature 2 is the charging points with communication technology. The function (F) layer for feature 6 represents a bulk and emergency generation in ( $\mathrm{Li}$ et al. 2012) and baseload power in (McGee et al. n.d.). The business (B) layer for feature 1 represents the reduction of charge for electricity and promotes load balance in (Santos et al. 2015), subscription agreement in (Budde Christensen et al. 2012), and financial leasing from the government to public transport companies in (Zhong and You 2012).

Furthermore, the information (I) layer for feature 15 represents CANbus protocol sending a basic set of information such as State-of-Charge, State-of-Health, vehicle position, available energy, charging time, etc. in (Santos et al. 2015). In the use case of (Rezania and Prüggler 2012), the information layer represents the driving pattern send from EV owner to aggregator and the tariffs and charging schedule send back to the owner from the aggregator. The communication (Cc) layer for feature 10 represents SAE J1772 charging standard and negative-side signaling using CANbus protocol in (McGee et al. n.d.). Meanwhile, the use case of (McGee et al. n.d.) includes analog communication with non-intelligent EVs and digital communication enabling V2G with intelligent EVs, and the use case of (Nicanfar et al. 2013) has an identity-based cryptography communication in the communication layer.

\section{Discussion}

\section{Technical details for identified features}

This paper finds that each feature has identical focuses on the three dimensions in the SGAM framework, based on the feature focuses, the 17 identified features can be categorized as in Table 9. Table 9 shows the current focuses of EV solutions in

Table 9 Category of 17 identified features

\begin{tabular}{ll}
\hline Category & Features \\
\hline EV charging & EV charging based on electricity production by DERs (Feature 7) \\
& EV and battery charging at charging stations (Features 4 \& 11) \\
Algorithm & Smart charging algorithm and optimization (Features 3 \& 5) \\
Communication & $\begin{array}{l}\text { Communication between EVs and others (including charging points, and the grid, energy } \\
\text { scheduler and data aggregator) (Features 2,10, 15, 16) }\end{array}$ \\
$\begin{array}{l}\text { Load } \\
\text { management }\end{array}$ & Load management by DSO, energy scheduler and data aggregator (Feature 14) \\
$\begin{array}{l}\text { Energy } \\
\text { flexibility }\end{array}$ & $\begin{array}{l}\text { Grid operator (Feature 13), datacenter and database (Feature 12), broker (Feature 17), } \\
\text { Involved actors }\end{array}$ \\
\hline
\end{tabular}


Table 10 Communication technical details

\begin{tabular}{|c|c|c|c|}
\hline Feature & $\begin{array}{l}\text { Domain } \\
\text { layers } \\
(G, T, D, D E R, C)\end{array}$ & $\begin{array}{l}\text { Zone layers } \\
(\mathrm{P}, \mathrm{F}, \mathrm{S}, \mathrm{O}, \mathrm{E}, \mathrm{M})\end{array}$ & $\begin{array}{l}\text { Interoperability } \\
\text { layers } \\
(\mathrm{C}, \mathrm{F}, \mathrm{B}, \mathrm{I}, \mathrm{Cc})\end{array}$ \\
\hline Communication between EVs and the grid (Feature 2) & $0,0,0,4,4$ & $4,4,0,0,0,0$ & $4,3,0,1,1$ \\
\hline $\begin{array}{l}\text { Communication between EVs and charging equipment } \\
\text { (Feature 10) }\end{array}$ & $0,0,0,0,2$ & $2,0,0,0,0,0$ & $0,0,0,2,2$ \\
\hline Communication between EV and aggregator (Feature 15) & $0,0,2,2,2$ & $0,2,2,2,0,0$ & $0,1,1,2,1$ \\
\hline $\begin{array}{l}\text { Communication between EVs and energy scheduler and data } \\
\text { aggregator (Feature 16) }\end{array}$ & $0,0,0,0,1$ & $0,1,0,0,0,0$ & $1,0,0,0,0$ \\
\hline
\end{tabular}

the literature. Therefore, if a simulation only focuses on the EV charging based on electricity production by DERs (Feature 7), it is easy to identify the technical details of this feature as shown in the corresponded row in Table 11 (in APPENDIX).

Meanwhile, features in the same category do not have the same technical details if the purposes are different. For instance, Table 10 shows that the four features in the communication categories have significant differences at the interoperability layers of the SGAM framework. These technical details and differences can support simulations to simulate the features with certain accuracy.

\section{Gap identification in the related literature}

This paper maps all use cases of EV solutions and business models in the literature into the SGAM framework not only to provide an overview of three dimensions of domains, zones, and interoperability layers but also to identify the gap in the research field.

The results show that the most popular EV use case within the targeted scope is the V2G concept, and 6 out of the 10 references discuss the EVs' potentials to work as energy storage (Li et al. 2012; McGee et al. n.d.; Nicanfar et al. 2013; Ahmad and Sivasubramani 2015; Santos et al. 2015; Rezania and Prüggler 2012). The V2G concept requires communication between EVs and the grid operators or balance responsible parties who often locate in the operation zone. In the SGAM framework, the communication layer includes communication standards which are only considered in (Santos et al. 2015). In general, all use cases in the references do not include standards in the information and communication layers. Furthermore, references, such as (Zhong and You 2012), do not consider any aspect of the smart grid architecture. Instead, (Zhong and You 2012) investigates a financial leasing business model for increasing the penetration of EVs.

As the V2G concept is not yet commercialized in the current electricity grids. Therefore, a completed mapping of the V2G use cases in the SGAM framework is recommended to investigate solutions and business models that can match the technical, market, and business requirements of a given energy ecosystem. Meanwhile, the technical details for the focused EV solutions in the literature are not precise enough to be directly implemented in simulations, maybe due to the focuses in each literature that are not for simulations.

\section{Conclusion}

This paper presents a methodology for identifying technical details of EV solutions in the energy system and identifying research gaps in the smart grid context. The 
proposed methodology includes two parts: A scoping review for literature search and collection; a SGAM framework driven literature analysis, that EV solutions and their business models found in the literature are mapped into the SGAM framework with three dimensions (Domains, Zones, and interoperability layers).

Two types (quantitative and qualitative) of scoping review are applied in the paper to ensure the selected literature matches the paper's scope. The quantitative scoping review results in a total number of 240 references and 10 references match the criteria based on the qualitative scoping review. The results show that the most popular EV use case within the targeted scope is the V2G concept, and 6 out of the 10 references discuss the EVs' potentials to work as energy storage.

Seventeen features are identified by mapping the EV use cases (solutions and business models) into the three dimensions (domain, zone, and interoperability layers) of the SGAM framework. The process at the Zone layer is the most popularly covered (mentioned 64 times), and enterprise at the Zone layer and communication at the interoperability layer are the least covered (mentioned 4 times each).

\section{Contributions}

Technical details are critical inputs to ensure the simulation quality for smart energy solutions and business models. However, no systematic method serves this purpose in the literature, and the majority of the literature is case-based. The developed methodology fills this gap with an investigation of the EV solutions in the energy systems. Meanwhile, the SGAM framework provides an architecture that can facilitate this process. The SGAM framework can be utilized by researchers and companies working with solutions in the smart grid to identify needed standards for the realization of the solution.

This proposed method provides a systematic approach for identifying research gaps in the smart grid. Meanwhile, the analysis of EVs use cases by using the proposed method, provides an overview of the literature on EVs in smart grid with the aspects of smart energy solutions and business models which was not yet fully discovered in the literature. The results can be the input as alternatives and multiple options for simulations to investigate the what-if scenarios.

\section{Limitation and future works}

The paper conducts the literature search in scientific databases to investigate the technical details, and other references, e.g., patents or technical reports are not included due to the main focus of the paper is to introduce the proposed methodology. Therefore, a more comprehensive and broad search is recommended especially for the technical details that have not been covered by the scientific literature. Meanwhile, to prove the proposed methodology can contribute to the mentioned simulations, agent-based simulation for EV solutions and business models are recommended with various scenarios, e.g., EV smart charging and participation in various electricity markets.

Furthermore, although business and market are included in the SGAM model, the aspects of policies, regulations, social and financial aspects are missing in the literature due to its technical focus. Although this paper uses the term 'technical details', details from other perspectives are recommended to be included for simulating smart energy solutions and business models in which many stakeholders and aspects are involved. 


\section{Appendix}

Table 11 Identified 17 features in the SGAM framework's three dimensions matching use cases in the articles

\begin{tabular}{ll}
\hline Feature number & SGAM domain-dimension \\
\hline 1 & Customer premises: \\
EVs or PHEVs as & EVs or PHEVs on the \\
storage for V2G & residential side (Hilshey et al. \\
& 2012) (Li et al. 2012) (McGee \\
& et al. n.d.) (Ahmad and \\
& Sivasubramani 2015) (Santos \\
& et al. 2015) (Yang and Tseng \\
& 2015) (Budde Christensen \\
& et al. 2012) (Rezania and \\
& Prüggler 2012) \\
& EV charging/discharging in \\
& residential building area \\
& (Nicanfar et al. 2013) \\
& Photovoltaic panels \\
& including inverters on the \\
& residential demand side \\
& (Rezania and Prüggler 2012) \\
& EVs at the commercial \\
& demand side (public \\
& transport commerce) (Zhong \\
& and You 2012) \\
& DER: \\
V2G enables the EVs to act \\
as energy storage (McGee \\
et al. n.d.) (Nicanfar et al. \\
2013) (Ahmad and \\
Sivasubramani 2015) (Li et al. \\
2012) (Santos et al. 2015) \\
(Rezania and Prüggler 2012) \\
\end{tabular}

2

Communication between EVs and the grid
SGAM zone-dimension

\section{Process:}

EVs or PHEVs consume

electricity (all $10 \mathrm{EV}$

solutions)

EVs or PHEVs inject power

back to the grid using $V 2 G$

(Li et al. 2012) (Nicanfar et al.

2013) (Ahmad and

Sivasubramani 2015)

Conversion of solar energy

to electricity (Rezania and

Prüggler 2012)

Photovoltaic panels

inverters on the

Rezania and Prüggler 2012)

EVs at the commercia

transport commerce) (Zhong

and You 2012)

as energy storage (McGee

et al. n.d.) (Nicanfar et al.

2012) (Santos et al. 2015)

\section{Customer premises:}

Smart meter is located at

the consumer (Hilshey et al. 2012) (Rezania and Prüggler 2012)

Charging points located at the home and building area network (Nicanfar et al. 2013) (Santos et al. 2015)

DER:

Charging point and smart meter receive electricity for charging from the grid (the grid is implicit going through the DER domain). (Hilshey et al. 2012) (Rezania and Prüggler 2012) (Nicanfar et al. 2013) (Santos et al. 2015)

SGAM interoperability layer-dimension

\section{Component:}

EVs or PHEVs as a physical

load component (all EV solutions)

V2G inverter (Rezania and

Prüggler 2012)

Photovoltaic including

inverter (Rezania and

Prüggler 2012)

Onboard monitoring, communication and control electronic units and/or GPS module in EVs \& chargers. (Santos et al. 2015) (McGee et al. n.d.)

Function:

EVs as battery storage through V2G (Nicanfar et al. 2013) (Ahmad and Sivasubramani 2015) (Li et al. 2012) (Santos et al. 2015) (Rezania and Prüggler 2012) Emergency power generation using V2G

(McGee et al. n.d.)

Data acquisition for optimizing EV charging and storage capabilities. (Santos et al. 2015)

\section{Business:}

Reduce electricity charge and promote load balance (Santos et al. 2015)

Financial leasing from the government to public transport companies (Zhong and You 2012)

\section{Process}

Smart meter measures electricity load (Hilshey et al. 2012) (Rezania and Prüggler 2012)

Charging point charges EVs (converting AC power to DC). (Nicanfar et al. 2013) (Santos et al. 2015)

\section{Field:}

Smart meter sends consumer-load. (Hilshey et al. 2012) (Rezania and Prüggler 2012)

Charging point communicates with the data collector (e.g. data center) via the communication components (Nicanfar et al. 2013)

Charging point includes telecommunication technology for data sharing with management units. (Santos et al. 2015)

\section{Component}

Smart meter (Advanced Metering Infrastructure) (Hilshey et al. 2012) (Rezania and Prüggler 2012)

Charging point (station or box) including communication or telecommunication technology (Nicanfar et al. 2013) (Santos et al. 2015)

\section{Function}

Connection between the charge management device and consumer's EV charging load (Hilshey et al. 2012) Send user identity to control unit (Nicanfar et al. 2013)

Communication via telecommunication technology (Santos et al. 2015)

\section{Information}

Send EV load and receive charging signals (Hilshey et al. 2012)

Communication 
Table 11 Identified 17 features in the SGAM framework's three dimensions matching use cases in the articles (Continued)

\begin{tabular}{|c|c|c|c|}
\hline Feature number & SGAM domain-dimension & SGAM zone-dimension & $\begin{array}{l}\text { SGAM interoperability } \\
\text { layer-dimension }\end{array}$ \\
\hline & & & $\begin{array}{l}\text { Public key encryption } \\
\text { system and Identity-based } \\
\text { cryptography (Nicanfar et al. } \\
\text { 2013) }\end{array}$ \\
\hline $\begin{array}{l}3 \\
\text { Smart charging } \\
\text { algorithm in the } \\
\text { charge } \\
\text { management } \\
\text { device }\end{array}$ & $\begin{array}{l}\text { Customer premises: } \\
\text { Home charging (Rezania and } \\
\text { Prüggler 2012) } \\
\text { DER: } \\
\text { Charge management device } \\
\text { linked with smart meter } \\
\text { sends and receives } \\
\text { information crossing the DER } \\
\text { domain } \\
\text { Distribution: } \\
\text { Charge management device } \\
\text { located at the transformer } \\
\text { (Hilshey et al. 2012) } \\
\text { Public charging station in } \\
\text { the distribution (Rezania and } \\
\text { Prüggler 2012) }\end{array}$ & $\begin{array}{l}\text { Process: } \\
\text { Charge management device } \\
\text { at the transformer (Hilshey } \\
\text { et al. 2012) } \\
\text { Charging and discharging } \\
\text { covers home charging and } \\
\text { public charging stations } \\
\text { (Rezania and Prüggler 2012) } \\
\text { Field: } \\
\text { Smart charging algorithm } \\
\text { (Hilshey et al. 2012) } \\
\text { Home charging and public } \\
\text { charging stations (Rezania } \\
\text { and Prüggler 2012) }\end{array}$ & $\begin{array}{l}\text { Component: } \\
\text { Charge management device } \\
\text { (Hilshey et al. 2012) } \\
\text { Function: } \\
\text { The charge management } \\
\text { device monitors } \\
\text { instantaneous loads and } \\
\text { sends charging signals to } \\
\text { EVs (Hilshey et al. 2012) } \\
\text { Smart charging algorithm } \\
\text { reduces transformer aging } \\
\text { (Hilshey et al. 2012) } \\
\text { Charging and discharging to } \\
\text { provide energy for the } \\
\text { control market (Rezania and } \\
\text { Prüggler 2012) } \\
\text { Information: } \\
\text { Send \& receive charging } \\
\text { signals to \& from smart } \\
\text { meter (Hilshey et al. 2012) }\end{array}$ \\
\hline $\begin{array}{l}4 \\
\text { EV and battery } \\
\text { charging at } \\
\text { charging stations }\end{array}$ & $\begin{array}{l}\text { Distribution: } \\
\text { The medium to low voltage } \\
\text { transformer (Hilshey et al. } \\
\text { 2012) } \\
\text { Charging station is } \\
\text { connected to the } \\
\text { distribution grid (Rezania } \\
\text { and Prüggler 2012) (Budde } \\
\text { Christensen et al. 2012) }\end{array}$ & $\begin{array}{l}\text { Process: } \\
\text { Transform voltage to the } \\
\text { domestic consumer level } \\
\text { (Hilshey et al. 2012) } \\
\text { EV electricity consumption. } \\
\text { (Budde Christensen et al. } \\
\text { 2012) (Rezania and Prüggler } \\
\text { 2012) } \\
\text { Charge batteries at the } \\
\text { battery switching station } \\
\text { (Budde Christensen et al. } \\
\text { 2012) } \\
\text { Field: } \\
\text { Protection equipment in the } \\
\text { transformer (Hilshey et al. } \\
\text { 2012) } \\
\text { Charging/battery switching } \\
\text { stations contain a smart } \\
\text { meter and control device } \\
\text { that manages EV charging } \\
\text { based on grid conditions } \\
\text { (Budde Christensen et al. } \\
\text { 2012) } \\
\text { Field equipment is assumed } \\
\text { to be part of the public } \\
\text { charging station (Rezania } \\
\text { and Prüggler 2012) } \\
\text { Station: } \\
\text { The transformer (Hilshey } \\
\text { et al. 2012) } \\
\text { Charging/battery switching } \\
\text { stations (Budde Christensen } \\
\text { et al. 2012) } \\
\text { The public charging station } \\
\text { includes the functional } \\
\text { aggregation of charging } \\
\text { multiple EVs at the same } \\
\text { location (Rezania and } \\
\text { Prüggler 2012) }\end{array}$ & $\begin{array}{l}\text { Component: } \\
\text { Medium to low voltage } \\
\text { transformer (Hilshey et al. } \\
\text { 2012) } \\
\text { Distributed charging spots } \\
\text { (Budde Christensen et al. } \\
\text { 2012) } \\
\text { EVs as a load at public } \\
\text { charging spots (Budde } \\
\text { Christensen et al. 2012) } \\
\text { Charging infrastructure } \\
\text { (Budde Christensen et al. } \\
\text { 2012) } \\
\text { Public charging station } \\
\text { (Rezania and Prüggler 2012) } \\
\text { Function: } \\
\text { Reduce voltage level for } \\
\text { domestic consumers } \\
\text { (Hilshey et al. 2012) } \\
\text { Charge or switch batteries } \\
\text { (Budde Christensen et al. } \\
\text { 2012) } \\
\text { The company acts as a } \\
\text { smart grid operator by } \\
\text { controlling the charging } \\
\text { spots (Budde Christensen } \\
\text { et al. 2012) }\end{array}$ \\
\hline 5 & All domains: & Operation: & Function: \\
\hline
\end{tabular}


Table 11 Identified 17 features in the SGAM framework's three dimensions matching use cases in the articles (Continued)

\begin{tabular}{|c|c|c|c|}
\hline Feature number & SGAM domain-dimension & SGAM zone-dimension & $\begin{array}{l}\text { SGAM interoperability } \\
\text { layer-dimension }\end{array}$ \\
\hline $\begin{array}{l}\text { Optimization in } \\
\text { fleet charging } \\
\text { management }\end{array}$ & $\begin{array}{l}\text { The optimization considers } \\
\text { thermal power plants, wind } \\
\text { turbines, PHEV fleet, and } \\
\text { regular load (Li et al. 2012) } \\
\text { Customer premises } \\
\text { Operating EVs from both } \\
\text { home charging and public } \\
\text { charging to help grid } \\
\text { balance (Rezania and } \\
\text { Prüggler 2012) }\end{array}$ & $\begin{array}{l}\text { The optimization is assumed } \\
\text { to be managed by a PHEV } \\
\text { fleet charging management } \\
\text { systems (Li et al. 2012) } \\
\text { The aggregator function can } \\
\text { be seen as EV fleet } \\
\text { management which is } \\
\text { located in the operation } \\
\text { zone (Rezania and Prüggler } \\
\text { 2012) }\end{array}$ & $\begin{array}{l}\text { Optimization with the } \\
\text { objective to minimize the } \\
\text { expected cumulative cost ( } \mathrm{Li} \\
\text { et al. 2012) } \\
\text { Aggregator/service provider } \\
\text { (Rezania and Prüggler 2012) } \\
\text { Business: } \\
\text { Minimizing costs (Li et al. } \\
\text { 2012) } \\
\text { Information: } \\
\text { Provide and activate control } \\
\text { energy (Rezania and } \\
\text { Prüggler 2012) }\end{array}$ \\
\hline $\begin{array}{l}6 \\
\text { Generation units } \\
\text { considering the } \\
\text { number of EVs }\end{array}$ & $\begin{array}{l}\text { Generation: } \\
\text { Electricity generation (Li } \\
\text { et al. 2012) (McGee et al. } \\
\text { n.d.) } \\
\text { Power plant cost } \\
\text { minimization (Ahmad and } \\
\text { Sivasubramani 2015) }\end{array}$ & $\begin{array}{l}\text { Process: } \\
\text { Convert fuel to electricity (Li } \\
\text { et al. 2012) (McGee et al. } \\
\text { n.d.) } \\
\text { Power plants minimization } \\
\text { (Ahmad and Sivasubramani } \\
\text { 2015) }\end{array}$ & $\begin{array}{l}\text { Component: } \\
\text { Multiple thermal power } \\
\text { plants and backup diesel } \\
\text { generators (Li et al. 2012) } \\
\text { Baseload power generation } \\
\text { units, e.g., thermal power } \\
\text { plants. (McGee et al. n.d.) } \\
\text { Function: } \\
\text { Bulk generation and } \\
\text { emergency generation } \\
\text { (diesel generators) (Li et al. } \\
\text { 2012) } \\
\text { Power generation for } \\
\text { baseload (McGee et al. n.d.) } \\
\text { Business: } \\
\text { Minimize generation cost } \\
\text { and power plants emission } \\
\text { considering the number of } \\
\text { EVs (Ahmad and } \\
\text { Sivasubramani 2015) }\end{array}$ \\
\hline $\begin{array}{l}7 \\
\text { EV charging based } \\
\text { on electricity } \\
\text { production by } \\
\text { DERs }\end{array}$ & $\begin{array}{l}\text { DER: } \\
\text { Wind turbines (Li et al. 2012) } \\
\text { (McGee et al. n.d.) (Budde } \\
\text { Christensen et al. 2012) } \\
\text { Photovoltaics (McGee et al. } \\
\text { n.d.) } \\
\text { DERs (Yang and Tseng 2015) } \\
\text { Energy storage (Rezania and } \\
\text { Prüggler 2012) }\end{array}$ & $\begin{array}{l}\text { Process: } \\
\text { Convert wind energy to } \\
\text { electricity (Li et al. 2012) } \\
\text { (McGee et al. n.d.) (Budde } \\
\text { Christensen et al. 2012) } \\
\text { Convert solar energy to } \\
\text { electricity (McGee et al. n.d.) } \\
\text { Convert energy to electricity } \\
\text { (Yang and Tseng 2015) } \\
\text { Electricity consumption and } \\
\text { generation (Rezania and } \\
\text { Prüggler 2012) }\end{array}$ & $\begin{array}{l}\text { Component: } \\
\text { Wind turbines (Li et al. 2012) } \\
\text { (McGee et al. n.d.) (Budde } \\
\text { Christensen et al. 2012) } \\
\text { Photovoltaics (McGee et al. } \\
\text { n.d.) } \\
\text { DER (not specified in paper) } \\
\text { (Yang and Tseng 2015) } \\
\text { Electricity energy storage } \\
\text { (batteries) (Rezania and } \\
\text { Prüggler 2012) } \\
\text { Business: } \\
\text { Charging when there is a } \\
\text { high wind electricity } \\
\text { production at a lower } \\
\text { electricity price (Budde } \\
\text { Christensen et al. 2012) }\end{array}$ \\
\hline $\begin{array}{l}8 \\
\text { Charging } \\
\text { equipment } \\
\text { enables V2G }\end{array}$ & $\begin{array}{l}\text { Customer premises: } \\
\text { EV supply equipment is } \\
\text { located at the demand side } \\
\text { (McGee et al. n.d.) } \\
\text { DER: } \\
\text { EV supply equipment } \\
\text { enables V2G for energy } \\
\text { storage (McGee et al. n.d.) }\end{array}$ & $\begin{array}{l}\text { Process: } \\
\text { AC is converted to DC to } \\
\text { charge the EV battery and } \\
\text { vice versa for V2G (McGee } \\
\text { et al. n.d.) }\end{array}$ & $\begin{array}{l}\text { Component: } \\
\text { EV supply equipment } \\
\text { (intelligent charging box) } \\
\text { (McGee et al. n.d.) } \\
\text { Function: } \\
\text { Charging and discharging } \\
\text { logic (McGee et al. n.d.) }\end{array}$ \\
\hline $\begin{array}{l}9 \\
\text { Participation in } \\
\text { electricity markets }\end{array}$ & $\begin{array}{l}\text { All domains beside } \\
\text { transmission: } \\
\text { supply and consume } \\
\text { electricity via market } \\
\text { participation (McGee et al. } \\
\text { n.d.; Santos et al. 2015; }\end{array}$ & $\begin{array}{l}\text { Market: } \\
\text { Participation in the energy } \\
\text { control/regulation market } \\
\text { (McGee et al. n.d.; Santos } \\
\text { et al. 2015) (Budde } \\
\text { Christensen et al. 2012) }\end{array}$ & $\begin{array}{l}\text { Business: } \\
\text { The use of EVs to bid into } \\
\text { the regulation market } \\
\text { (McGee et al. n.d.) } \\
\text { The Portuguese energy } \\
\text { market (Santos et al. 2015) }\end{array}$ \\
\hline
\end{tabular}


Table 11 Identified 17 features in the SGAM framework's three dimensions matching use cases in the articles (Continued)

\begin{tabular}{|c|c|c|c|}
\hline Feature number & SGAM domain-dimension & SGAM zone-dimension & $\begin{array}{l}\text { SGAM interoperability } \\
\text { layer-dimension }\end{array}$ \\
\hline & $\begin{array}{l}\text { Budde Christensen et al. } \\
\text { 2012; Rezania and Prüggler } \\
\text { 2012) }\end{array}$ & (Rezania and Prüggler 2012) & $\begin{array}{l}\text { Nord Pool electricity spot } \\
\text { market (Budde Christensen } \\
\text { et al. 2012) } \\
\text { Austrian control energy } \\
\text { market (Rezania and } \\
\text { Prüggler 2012) } \\
\text { Function: } \\
\text { Time-of-Use tariff business } \\
\text { model (Santos et al. 2015) }\end{array}$ \\
\hline $\begin{array}{l}10 \\
\text { Communication } \\
\text { between EVs and } \\
\text { charging } \\
\text { equipment }\end{array}$ & $\begin{array}{l}\text { Customer premises: } \\
\text { Communication and } \\
\text { information between the EV } \\
\text { and charging point EVs and } \\
\text { charging point on the } \\
\text { demand side (McGee et al. } \\
\text { n.d.) (Nicanfar et al. 2013) }\end{array}$ & $\begin{array}{l}\text { Process: } \\
\text { Communication between EV } \\
\text { point/ supply equipment } \\
\text { and EV (McGee et al. n.d.; } \\
\text { Nicanfar et al. 2013) }\end{array}$ & $\begin{array}{l}\text { Communication: } \\
\text { SAE J1772 charging standard } \\
\text { (McGee et al. n.d.) } \\
\text { Negative-side signaling } \\
\text { using CANbus (McGee et al. } \\
\text { n.d.) } \\
\text { Identity-based cryptography } \\
\text { (Nicanfar et al. 2013) } \\
\text { Information: } \\
\text { Voltage level as control } \\
\text { signal (McGee et al. n.d.) } \\
\text { EV identity (Nicanfar et al. } \\
\text { 2013) }\end{array}$ \\
\hline $\begin{array}{l}11 \\
\text { EV charging at } \\
\text { public charging } \\
\text { points/ fast- } \\
\text { charging stations }\end{array}$ & $\begin{array}{l}\text { Distribution: } \\
\text { Public charging points in } \\
\text { distrbuition grid (Nicanfar } \\
\text { et al. 2013) } \\
\text { Transmission: } \\
\text { Fast charging stations in } \\
\text { transmission grid (Nicanfar } \\
\text { et al. 2013) }\end{array}$ & $\begin{array}{l}\text { Process: } \\
\text { EV Charging (Nicanfar et al. } \\
\text { 2013) }\end{array}$ & $\begin{array}{l}\text { Component: } \\
\text { EVs at public charging } \\
\text { points and fast-charging sta- } \\
\text { tions (Nicanfar et al. 2013) }\end{array}$ \\
\hline $\begin{array}{l}12 \\
\text { Data collector or } \\
\text { database (data } \\
\text { center) }\end{array}$ & $\begin{array}{l}\text { Distribution and } \\
\text { transmission: } \\
\text { Data collector or databases } \\
\text { such as data (Nicanfar et al. } \\
\text { 2013) (Santos et al. 2015) }\end{array}$ & $\begin{array}{l}\text { Station: } \\
\text { The data collector or } \\
\text { database is a data } \\
\text { concentration (Nicanfar et al. } \\
\text { 2013) (Santos et al. 2015) }\end{array}$ & $\begin{array}{l}\text { Component: } \\
\text { Data collector or database } \\
\text { e.g. data center (Nicanfar } \\
\text { et al. 2013) (Santos et al. } \\
\text { 2015) } \\
\text { Function: } \\
\text { A cloud solution, smart grid } \\
\text { server (Nicanfar et al. 2013) }\end{array}$ \\
\hline $\begin{array}{l}13 \\
\text { Grid operator or } \\
\text { DSO control } \\
\text { operations }\end{array}$ & $\begin{array}{l}\text { Distribution: } \\
\text { The grid operator is the DSO } \\
\text { (Santos et al. 2015) }\end{array}$ & $\begin{array}{l}\text { Operation: } \\
\text { The grid operator has power } \\
\text { system control operations } \\
\text { (Santos et al. 2015) } \\
\text { Enterprise: } \\
\text { Grid operators have } \\
\text { commercial and } \\
\text { organizational processes } \\
\text { (Santos et al. 2015) }\end{array}$ & $\begin{array}{l}\text { Function: } \\
\text { Grid operator (Santos et al. } \\
\text { 2015) }\end{array}$ \\
\hline $\begin{array}{l}14 \\
\text { Load management } \\
\text { by DSO, energy } \\
\text { scheduler and } \\
\text { data aggregator }\end{array}$ & $\begin{array}{l}\text { Distribution: } \\
\text { The load management at } \\
\text { the DSO (Santos et al. 2015) }\end{array}$ & $\begin{array}{l}\text { Operation: } \\
\text { Load management (Santos } \\
\text { et al. 2015) }\end{array}$ & $\begin{array}{l}\text { Component: } \\
\text { Computers/controllers } \\
\text { (Santos et al. 2015) } \\
\text { Function: } \\
\text { Computers/controller as an } \\
\text { energy scheduler and data } \\
\text { aggregator. (Santos et al. } \\
\text { 2015) } \\
\text { The energy scheduler and } \\
\text { data aggregator does load } \\
\text { management of residential } \\
\text { end-users based on an } \\
\text { optimization algorithm (San- } \\
\text { tos et al. 2015) } \\
\text { Business: } \\
\text { The objective of the }\end{array}$ \\
\hline
\end{tabular}


Table 11 Identified 17 features in the SGAM framework's three dimensions matching use cases in the articles (Continued)

\begin{tabular}{|c|c|c|c|}
\hline Feature number & SGAM domain-dimension & SGAM zone-dimension & $\begin{array}{l}\text { SGAM interoperability } \\
\text { layer-dimension }\end{array}$ \\
\hline & & & $\begin{array}{l}\text { optimization is to reduce } \\
\text { charging costs (Santos et al. } \\
\text { 2015) }\end{array}$ \\
\hline $\begin{array}{l}15 \\
\text { Communication } \\
\text { between EV and } \\
\text { aggregator }\end{array}$ & $\begin{array}{l}\text { Customer premises, DER, } \\
\text { and distribution: } \\
\text { Communication standards } \\
\text { and information flow } \\
\text { between charging point and } \\
\text { energy scheduler and data } \\
\text { aggregator. (Santos et al. } \\
\text { 2015) } \\
\text { Information flow between } \\
\text { EVs and the aggregator } \\
\text { (Rezania and Prüggler 2012) }\end{array}$ & $\begin{array}{l}\text { Field, station, and } \\
\text { operation: } \\
\text { Communication standards } \\
\text { and information flow } \\
\text { between charging point, } \\
\text { energy scheduler and data } \\
\text { aggregator (Santos et al. } \\
2015 \text { ) } \\
\text { Information flow between } \\
\text { EVs (through field } \\
\text { equipment) and aggregator } \\
\text { (Rezania and Prüggler 2012) }\end{array}$ & $\begin{array}{l}\text { Communication: } \\
\text { ISO } 15118 \text { for charging } \\
\text { point. } \\
\text { IEEE } 802.11 \text {.p or WiMax or } \\
\text { 2G/3G/4G for wireless } \\
\text { communication (Santos } \\
\text { et al. 2015) } \\
\text { Information: } \\
\text { CANbus protocol sends a } \\
\text { basic set of information such } \\
\text { as State-of-Charge, State-of- } \\
\text { Health, Vehicle position, } \\
\text { available energy, charging } \\
\text { time, etc. (Santos et al. 2015) } \\
\text { Driving pattern sent from EV } \\
\text { owner to aggregator } \\
\text { (Rezania and Prüggler 2012) } \\
\text { Tariffs and charging } \\
\text { schedule sent to EV from } \\
\text { aggregator (Rezania and } \\
\text { Prüggler 2012) }\end{array}$ \\
\hline $\begin{array}{l}16 \\
\text { Communication } \\
\text { between EVs and } \\
\text { energy scheduler } \\
\text { and data } \\
\text { aggregator }\end{array}$ & $\begin{array}{l}\text { Customer premises: } \\
\text { Cellular technologies are } \\
\text { assumed together with EVs } \\
\text { (Santos et al. 2015) }\end{array}$ & $\begin{array}{l}\text { Field: } \\
\text { Wireless connection } \\
\text { between EVs, energy } \\
\text { scheduler and data } \\
\text { aggregator (Santos et al. } \\
\text { 2015) }\end{array}$ & $\begin{array}{l}\text { Component: } \\
\text { Cellular technologies } \\
\text { (antennas) (Santos et al. } \\
\text { 2015) }\end{array}$ \\
\hline $\begin{array}{l}17 \\
\text { A broker between } \\
\text { EV owner and } \\
\text { energy market }\end{array}$ & $\begin{array}{l}\text { Distribution and } \\
\text { transmission: } \\
\text { The company controls } \\
\text { charging spots in the } \\
\text { distribution grid to balance } \\
\text { the distribution and } \\
\text { transmission grids (Budde } \\
\text { Christensen et al. 2012) }\end{array}$ & $\begin{array}{l}\text { Station and operation: } \\
\text { Utilize the data acquired in } \\
\text { the station to operate } \\
\text { processes (Budde } \\
\text { Christensen et al. 2012) } \\
\text { Enterprise: } \\
\text { Company Better place } \\
\text { (Budde Christensen et al. } \\
\text { 2012) } \\
\text { Market: } \\
\text { Bidding into spot markets } \\
\text { (Budde Christensen et al. } \\
\text { 2012) }\end{array}$ & $\begin{array}{l}\text { Business: } \\
\text { Battery leasing and EV } \\
\text { monitoring (Budde } \\
\text { Christensen et al. 2012) } \\
\text { Energy demand Bidding into } \\
\text { spot markets (Budde } \\
\text { Christensen et al. 2012) } \\
\text { Provide intelligent charging } \\
\text { to the charging } \\
\text { infrastructure (Budde } \\
\text { Christensen et al. 2012) } \\
\text { The company acts as a } \\
\text { broker between the energy } \\
\text { market and EV owner } \\
\text { (Budde Christensen et al. } \\
\text { 2012) } \\
\text { Charging when electricity } \\
\text { price is low (Budde } \\
\text { Christensen et al. 2012) } \\
\text { Eliminate the uncertainties } \\
\text { about battery degradation } \\
\text { for EV adoption (Budde } \\
\text { Christensen et al. 2012) }\end{array}$ \\
\hline
\end{tabular}

\section{Abbreviations}

CO2: Carbon dioxide; DER: Distributed Energy Resources; EU: European Union; EV: Electric Vehicle; G2V: Grid-to-Vehicle; PHEV: Plug-in Hybrid Electric Vehicle; SCADA: Supervisory Control And Data Acquisition; SGAM: Smart Grid Architecture Model; V2G: Vehicle-to-Grid

Acknowledgments

Not applicable. 


\section{About this supplement}

This article has been published as part of Energy Informatics Volume 4, Supplement 2 2021: Proceedings of the Energy Informatics.Academy Conference Asia 2021. The full contents of the supplement are available at <https:// energyinformatics.springeropen.com/articles/supplements/volume-4-supplement-2>.

\section{Authors' contributions}

K.C. developed the first draft of this paper along with additional information from the corresponding work and contribution of the co-authors in the early and late stages of the project. All co-authors read, commented, and approved the final manuscript.

\section{Funding}

This work is part of the national project- Flexible Energy Denmark FED funded by Innovation Fund Denmark.

\section{Declarations}

\section{Ethics approval and consent to participate}

Not applicable.

\section{Consent for publication}

Not applicable.

\section{Competing interests}

The authors declare that they have no competing interests.

\section{Author details}

${ }^{1}$ Center for Energy Informatics, Mærsk Mc-Kinney Møller Institute, University of Southern Denmark, 5230 Odense, Denmark. ${ }^{2}$ Center for Health Informatics and Technology, Mærsk Mc-Kinney Møller Institute, University of Southern Denmark, 5230 Odense, Denmark. ${ }^{3}$ Yves Demazeau, Laboratoire d'Informatique de Grenoble, Centre National de la Recherche Scientifique, 38000 Grenoble, France.

\section{Published: 24 September 2021}

\section{References}

Ahmad MS, Sivasubramani S (2015) leee. Optimal Solution of Plug in Hybrid Electric Vehicles to Minimize Cost and Emission in a Smart Grid - A Developing Country View. 2015 leee Power \& Energy Society General Meeting. IEEE Power and Energy Society General Meeting PESGM

Arksey H, O'Malley L (2005) Scoping studies: towards a methodological framework. Int J Soc Res Methodol 8(1):19-32. https:// doi.org/10.1080/1364557032000119616

Billanes JD, Ma Z, Jørgensen BN (2017) Consumer central energy flexibility in office buildings. J Energy Power Eng 2017(11): $621-630$

Budde Christensen T, Wells P, Cipcigan L (2012) Can innovative business models overcome resistance to electric vehicles? Better place and battery electric cars in Denmark. Energy Policy 48:498-505. https://doi.org/10.1016/j.enpol.2012.05.054

CEN-CENELEC-ETSI Smart Grid Coordination Group. CEN-CENELEC-ETSI Smart Grid Coordination Group - Smart Grid Reference Architecture. 2012

Christensen K, Demazeau Y, Ma Z, Jørgensen BN (2020a) Agent-based Modeling of Climate and Electricity Market Impact on Commercial Greenhouse Growers' Demand Response Adoption. In: THE 2020 RIVF international conference on computing and communication technologies; 6-7 April. IEEE, Ho Chi Minh City

Christensen K, Ma Z, Demazeau Y, Jørgensen BN (2020b) Agent-based modeling for optimizing CO2 reduction in commercial greenhouse production with the implicit demand response. The 6th IEEJ international workshop on sensing, actuation, motion control, and optimization (SAMCON2020); 14-16 march; Shibaura Institute of Technology. IEEJ, Tokyo

Energistyrelsen. Basisfremeskrivning: Energi- og klimafremskrivning frem til 2030 under fravær af nye tiltag. 2019

Fatras N, Ma Z, Jørgensen BN (2020) Suitability assessment of electricity market mechanisms for electric vehicle grid integration. 2020 IEEE International Conference on Power Systems Technology (POWERCON); 2020 14-16 Sept

Fatras N, Ma Z, Jørgensen BN (2021) System Architecture Modelling Framework Applied to the Integration of Electric Vehicles in the Grid. Springer International Publishing, Cham

Hilshey AD, Rezaei P, Hines PDH, Frolik J (2012) leee. Electric Vehicle Charging: Transformer Impacts and Smart, Decentralized Solutions. 2012 leee Power and Energy Society General Meeting. IEEE Power and Energy Society General Meeting PESGM

Howard DA, Ma Z, Engvang JA, Hagenau M, Jørgensen KL, Olesen JF et al (2020b) Optimization of energy flexibility in cooling process for brewery fermentation with multi-agent simulation. In: The 6th IEEJ international workshop on sensing, actuation, motion control, and optimization (SAMCON2020); 14-16 march; Shibaura Institute of Technology. IEEJ, Tokyo

Howard DA, Ma Z, Jørgensen BN (2020a) Digital Twin Framework for Energy Efficient Greenhouse Industry. International Conference on Practical Applications of Agents and Multi-Agent Systems; L'Aquila, Italy

Li YF, Kampuang R, Wang P, Niyato D, Han Z (2012) leee. An Energy Efficient Solution: Integrating Plug-In Hybrid Electric Vehicle in Smart Grid with Renewable Energy. 2012 leee conference on computer communications workshops. IEEE Conference on Computer Communications Workshops, pp 73-78

Ma Z (2019a) Business ecosystem modeling- the hybrid of system modeling and ecological modeling: an application of the smart grid. Energy Inform 2(1):35. https://doi.org/10.1186/s42162-019-0100-4

Ma Z (2019b) Business ecosystem modeling - the hybrid of system modeling and ecological modeling: an application of the smart grid. Energy Inform. 2(1). https://doi.org/10.1186/s42162-019-0100-4 
Ma Z, Asmussen A, Jørgensen B (2018) Industrial consumers' smart grid adoption: influential factors and participation phases. Energies. 11(1):182. https://doi.org/10.3390/en11010182

Ma Z, Badi A, Jørgensen BN (2016) Market opportunities and barriers for smart buildings. 2016 IEEE green energy and systems conference (IGSEC); 2016 6-7 Nov, Long Beach

Ma Z, Billanes J, Jørgensen B (2017a) Aggregation potentials for buildings-business models of demand response and virtual power plants. Energies 10(10):1646

Ma Z, Christensen K, Jorgensen BN (2021) Business ecosystem architecture development: a case study of electric vehicle home charging energy informatics

Ma Z, Friis HTA, Mostrup CG, Jørgensen BN (2017b) Energy Flexibility Potential of Industrial Processes in the Regulating Power Market. the 6th International Conference on Smart Cities and Green ICT Systems

Ma Z, Jørgensen BN (2018) Energy Flexibility of The Commercial Greenhouse Growers, The Potential and Benefits of Participating in The Electricity Market. In: IEEE PES Innovative Smart Grid Technologies North America (ISGT North America 2018); 2018 19-22 Feb. IEEE, Washington, DC

Ma Z, Knotzer A, Billanes JD, Jørgensen BN (2020) A literature review of energy flexibility in district heating with a survey of the stakeholders' participation. Renew Sust Energ Rev 123:109750. https://doi.org/10.1016/j.rser.2020.109750

Ma Z, Schultz MJ, Christensen K, Værbak M, Demazeau Y, Jørgensen BN (2019) The application of ontologies in multi-agent Systems in the Energy Sector: a scoping review. Energies. 12(16):3200. https://doi.org/10.3390/en12163200

McGee R, Waite N, Wells N, Kiamilev FE, Kempton WM (n.d.) Vehicle to grid: electric vehicles as an energy storage solution. In: Dhar NK, Balaya P, Dutta AK (eds) Energy Harvesting and Storage: Materials, Devices, and Applications Iv. Proceedings of SPIE. 87282013

Nicanfar H, TalebiFard P, Hosseininezhad S, Leung VCM, Damm M (2013) Security and privacy of electric vehicles in the smart grid context: problem and solution. In: Proceedings of the third ACM international symposium on Design and analysis of intelligent vehicular networks and applications; Barcelona, Spain. 2512926: ACM, pp 45-54

Rezania R, Prüggler W (2012) Business models for the integration of electric vehicles into the Austrian energy system. 2012 9th International Conference on the European Energy Market; 2012 10-12 May

Santos VDN, Goncalves JMR, Tavares PF, Trovao JP (2015) leee. A Novel ICT Solution for Electric Vehicles Integration on Smart Grids. 2015 leee vehicle power and propulsion conference. IEEE Vehicle Power and Propulsion Conference

Værbak M, Ma Z, Christensen K, Demazeau Y, Jørgensen BN (2019) Agent-Based Modelling of Demand-Side Flexibility Adoption in Reservoir Pumping. IV International Congress of Research in Sciences and Humanities Science and Humanities International Research Conference (SHIRCON 2019); 12-15 November. IEEE, Lima

Yang N-C, Tseng W-C (2015) Adaptive three-phase power-flow solutions for smart grids with plug-in hybrid electric vehicles Int J Electr Power Energy Syst 64:1166-1175. https://doi.org/10.1016/j.jijepes.2014.08.007

Zheng M, Prljaca Z, Jørgensen BN (2016) The international electricity market infrastructure-insight from the nordic electricity market. 2016 13th International Conference on the European Energy Market (EEM); 2016 6-9 June

Zhong Z, You J (2012) Business model of clean energy vehicles industry based on option. 2012 6th International Conference on New Trends in Information Science, Service Science and Data Mining (ISSDM2012); 2012 23-25 Oct

Zhu T, Khajepour A, Zheng H (2016) Development of holistic corner control for electric vehicle using a new driver command interpreter. Proceedings of the International Conference on Artificial Intelligence and Robotics and the International Conference on Automation, Control and Robotics Engineering; Kitakyushu. Association for Computing Machinery, Japan p. Article 9

\section{Publisher's Note}

Springer Nature remains neutral with regard to jurisdictional claims in published maps and institutional affiliations.

\section{Submit your manuscript to a SpringerOpen ${ }^{\circ}$ journal and benefit from:}

- Convenient online submission

- Rigorous peer review

- Open access: articles freely available online

- High visibility within the field

- Retaining the copyright to your article

Submit your next manuscript at $\mathbf{s p r i n g e r o p e n . c o m ~}$ 